\title{
Optimisation of Food Supplement for Development of Nutritious Pasta by Utilizing Tulsi Powder
}

\author{
Piyush Mishra*, Devendra Kumar Bhatt \\ Institute of Food Technology (Center of Excellence), Bundelkhand University, Jhansi-284128, Uttar Pradesh, \\ India
}

\begin{abstract}
Pasta is a popular food and its quality can be measured by appearances of flavour and texture present study undertaken to evaluate the quality of pasta supplemented with deferent quantity of tulsi powder. In present study we developed three samples $(C, C 1, C 2$, and C3) of pasta using refined wheat flour and proportions of tulsi powder. Sample C was prepared as control containing only refined wheat flour (100\%), while sample C1 (refined wheat flour 99\% and tulsi powder 1\%), C2 (refined wheat flour 97\% and tulsi powder 3\%), C3 (refined wheat flour 95\% and tulsi powder 5\%) were prepared by changing the concentration of refined wheat flour and different tulsi powder. All the three samples were evaluated for the physicochemical properties (moisture content, ash value and texture analysis) nutritional properties (carbohydrate, protein, and fat), cooking time and sensory qualities. A tulsi powder fortified pasta product was successfully produced and it was observed as the concentration of tulsi powder was increased the cooking time also increased. On the basis of physicochemical \& nutritional properties cooking time and sensory qualities, pasta containing refined wheat flour (97\%) and tulsi powder (3\%) resulted in better quality having more nutritional elements and highest overall acceptability.
\end{abstract}

Keywords: Pasta, fortification, protein supplementation, nutrition, health conscious peoples.

\section{Introduction}

There is a worldwide interest in production and availability of convenient foods that provide quality nutrition. Pasta, is wheat-based product, it is a commonly consumed food as ready-to-eat option, or one requiring only minimal in home Preparation .Pasta is very popular and ready to eat snacks. it is mostly popular in children and The present generation. In India pasta is mostly preferred it is moving very fast without any most valuable effect. if its neutraceutical properties will enhance than it can be have a better effect and also easy to consume. Tulsi is a very useful to take his neutraceutical properties. Tulsi alternatively known as the holy basil or ocimum sanctum, tulsi is a common name in most Indian households. Easy to grow and widely found in the Indian subcontinent, not only is tulsi a revered, holy plant in Hinduism; it also finds its place in the ancient science of Ayurveda. Tulsi is commonly found in two varieties - the green coloured Lakshmi tulsi and the purple hued Krishna tulsi. Apart from the Indian subcontinent, it can also be found in tropical regions of most Southeast Asian countries.Tulsi is worshipped, is offered the gods and is grown in many Hindu households not in vain but for a well-established reason - this humble, inexpensive herb comes loaded with a host of benefits. Tulsi is extremely beneficial for humans. From warding off some of the most common ailments, strengthening immunity, fighting bacterial \& viral infections to combating and treating various hair and skin disorders - just a few leaves of tulsi when used regularly can help resolve a host of health and lifestyle related issues.Tulsi assumes utmost importance when it comes to Ayurveda and naturopathy. Its essential oils are used to treat number of ailments. In many research found "The essential oils found in tulsi, effectively act on our respiratory system". It is rich in antioxidants which help in mitigating stress and conditions like diabetes, high blood pressure and so on. "Tulsi has linoleic acid which is extremely beneficial for skin,", tulsi leaves have volatile and fixed oils which can help fight allergies, infections and pathogens. Tulsi paste as well as the powder has long been used in herbal and cosmetic products for its purifying, detoxifying and cleansing properties. Commonly paired with other herbs and ingredients like neem, giloy and turmeric, tulsi paste when applied on acne and pimples can ensure relief with lesser chances of repeat breakouts.

Tulsi can rightly be termed as one of the most commonly and widely used ingredients in many Indian home remedies. From regular fever to some of the deadliest and most fatal bacterial and viral infections - tulsi can help cure or to some extent, facilitate treating most diseases. Consuming a drink made by boiling tulsi leaves and adding about 2 grams of black pepper to it. This drink helps in building your immunity, acts as an antibacterial element and facilitates recovery from dengue. The quintessential kadha - a mix of ginger, tulsi leaves, peppercorn (crushed) in boiling hot water - is usually seen as a potion that can put most illnesses straight. Apart from these there is a bundle of other beneficial properties that this humble plant boasts of, take a look It acts as a detoxifying, cleansing and purifying agent - both from within and without. Therefore it is good for skin - both when consumed and applied topicallyIt is also effective in treating skin disorders, itching and issues 
like ringworms. It can be made into teas or can be had raw, powdered, paste or in form herbal supplements.5. It has antibiotic, anti-viral, anti-bacterial and anti-carcinogenic properties.6. It helps in relieving from fever, headache, sore throat, cold, cough, flu and chest congestion.7. It is also beneficial in treating respiratory ailments like chronic bronchitis, asthma et cetera.8. Helps relieve stress, strengthen immunity, and facilitate proper digestion.9. It is loaded with phytonutrients, essential oils, Vitamin A and C . Regular tulsi consumption can also aid in balancing various bodily processes.11. It counters elevated blood sugar levels and is therefore beneficial for diabetics.12. It helps in regulating uric acid levels in body, thereby elimination risks of developing kidney stones. It is also beneficial for those who have kidney stones.13. According to the Central Drug Research Institute, Lucknow, India, tulsi can help in maintaining normal levels of the stress hormone - cortisol in the body.14, It can wards off harmful effects of free radicals.15. Is great for dental health and for healthy gums.16. Is an effective insect repellant and can aid in treating insect bite.17. Is also beneficial in treating conditions like hepatitis, malaria, tuberculosis, dengue and swine flu.18. It is also known as adaptogen.Tulsi plant grows in rich and moist soil with ample sunlight. You can begin by planting it just a few centimetres below the soil with a light cover of dirt. Let it grow indoors till it's about 6-7 inch tall, after which the plant can be transferred outdoors. Tulsi should be planted right before monsoon, under intense heat.

\section{Material And Method}

\subsection{Procurements of raw material}

Tulsi powder usually, grinded and sundried and wheat flour (Triticum aestivam) is used and procured from local market.

\subsection{Evaluation of physicochemical properties of raw material}

The content of protein was determined as per (IS: 7219:1973): Kjeldhal method, protein content was obtained by using the conversion factor of 6.25 , crude fibre was determined by (IS: 11062) and carbohydrate content by difference method, ash and fat content were determined according to AOAC 2000 methods.

\subsection{Sample preparation}

Four Samples (C, C1, C2, and C3) were prepared using sample $\mathrm{C}$ as control containing only refined wheat flour (100\%), while sample C1, C2 and C3 were prepared using different concentration of refined wheat flour and tulsi powder. Proximate composition and concentration of different raw materials taken in the preparation of control (C) and other samples (C1-C3) is shown in Table 1. All the samples were passed separately through sieve no. 10 thrice to improve the mixing. Prepared samples were stored in an air tight polyethylene bag in cool and dry place for further study.

Table.1 Chemical composition of raw materials

\begin{tabular}{|l|l|c|c|c|}
\hline Ingredient & \multicolumn{1}{|l|}{ Sample } & $\mathrm{C} 2$ & $\mathrm{C} 3$ \\
\hline & $\mathrm{C}$ & $\mathrm{C} 1$ & 970 & 950 \\
\hline Refind wheat flour & 1000 & 990 & 30 & 50 \\
\hline Soya protein isolate & - & 10 & & \\
\hline
\end{tabular}

\subsection{Pasta Preparation}

Different samples of pasta $(\mathrm{C}, \mathrm{C} 1, \mathrm{C} 2$ and $\mathrm{C} 3)$ is prepared using different concentrations of refined wheat flour and tulsi powder in the ratio of 100:00; 99:01; 97:03, 95:05 respectively. In each case, an amount of $1000 \mathrm{~g}$ of the respective composition was taken for the preparation of pasta. Refined wheat flour and tulsi powder is mixed with optimum amount of water in the mixing chamber of pasta extruder (Le Monferrina Masoreo Arturo and C.S.N.C., Italy) for 10 minute to distribute the water uniformly. The moist flour aggregate was extruded through pasta extruder fitted with an adjustable die. The speed of revolving sharp blade cutter in the front of the die was adjusted so that the length of the pasta finished at $2 \mathrm{~cm}$ for each sample. Drying of final pasta sample was carried out in hot air oven at $75^{\circ} \mathrm{C}$ for $3 \mathrm{~h}$. The dried product was packed in polyethylene bags. The main objective of the drying was to reduce the moisture content of the sample to about $8-10 \%$. Final dried products of various samples were packed in high density polyethylene bags. The resultant dried products were then used for further study such as cooking time, chemical composition, viscosity, texture and sensory analysis.

\subsection{Evaluation and optimization of pasta samples}

The developed pasta products were analyzed for their different quality parameters. The cooking quality of samples was determined by the minimum cooking time as per AACC 2000. Rapid visco analyzer (RVA) was used to determine the pasting properties of raw material of pasta products. The texture of the product was determined with the help of stable micro system texture analyzer TA-XT2i. It was used in cutting mode to record the required force to cut the pasta sample. Sensory evaluation was carried out as per 9 point hedonic scale with the degree of liking: $1=$ extremely dislike, to $9=$ extremely like. Each pasta sample was cooked separately 
in a stainless steel pan, in the each case $100 \mathrm{~g}$ pasta sample was taken and cooked in $500 \mathrm{ml}$ of water. The pasta was added in to the boiling water and was boiled for the time already determined. Boiled pasta was then drained, fried in a pre standardized method by using oil, mustard, onion and tomato with salt and used for sensory evaluation. A ten member panel of panellists evaluated the cooked samples of pasta and marked their observations in the sensory card. Each of the samples was randomly numbered using a three-digit code. Pasta was evaluated for colour, texture, aroma, taste and overall acceptability.

\subsection{Statistical analysis.}

The results are expressed as Mean \pm SD (standard deviation). The statistical significance was analyzed using One-way Analysis of Variance (ANOVA) followed by Dunnett Multiple Comparisons Test by employing statistical software, Graph Pad, Instate 3. Differences between groups were considered significant at $\mathrm{P}<0.05$ level.

\subsection{Evaluation of chemical composition of raw material}

\section{Results and Discussions}

The composition of the raw material is depicted in Table 2

Table.2.Chemical composition of raw materials

\begin{tabular}{|l|l|l|l|l|l|}
\hline Raw material & Carbohydrate & Protein & Fat & Fibre & Ash \\
\hline Refined wheat flour & $72.66 \pm 0.02$ & $10.68 \pm 0.8$ & $1.18 \pm 0.09$ & $0.50 \pm 0.15$ & $3.62 \pm 0.03$ \\
\hline Tulsi powder & $16.80 \pm 0.01$ & $5.05 \pm 0.12$ & $0.30 \pm 0.02$ & $2.41 \pm 0.03$ & $1.26 \pm 0.01$ \\
\hline
\end{tabular}

\subsection{Nutritional composition of prepared pasta samples}

The protein content of $C, C 1, C 2$ and $C 3$ pasta samples were found to be 9.73, 9.58, 9.41, and 9.25 respectively. Fortification of pasta with different level of tulsi powder lightly decreases the carbohydrate, protein, fat and ash content of the final products. While fibre content of prepared tulsi pasta increases in comparison to control pasta, the result agreed with other researchers. The nutritional composition of prepared pasta samples is shown in Table 3.

Table.3. Nutritional composition of prepared pasta samples

\begin{tabular}{|l|l|l|l|l|l|}
\hline sample & Carbohydrate & Protein & Fat & Fibre & Ash \\
\hline C & $72.00 \pm 0.58$ & $9.72 \pm 0.24$ & $1.15 \pm 0.01$ & $0.48 \pm 0.01$ & $3.54 \pm 0.06$ \\
\hline C1 & $72.00 \pm 0.52$ & $9.46 \pm 0.92$ & $1.12 \pm 0.04$ & $0.52 \pm 0.06$ & $3.42 \pm 0.12$ \\
\hline C2 & $74.16 \pm 0.45$ & $9.41 \pm 0.91$ & $1.11 \pm 0.05$ & $0.52 \pm 0.02$ & $3.09 \pm 0.05$ \\
\hline C3 & $74.00 \pm 0.41$ & $9.21 \pm 0.61$ & $1.06 \pm 0.03$ & $0.56 \pm 0.07$ & $2.95 \pm 0.08$ \\
\hline
\end{tabular}

Note: All value are represented as Mean \pm S.E.M. (standard error mean), $n=6$; data were analyzed by one-way ANOVA (Analysis of variance) employing Dunnett Multiple Comparisons Test using Graph Pad, Instate 3 software. Where $\mathrm{C}=\mathrm{Control}$ sample, $\mathrm{C} 1=1 \%$ tulsi powder sample, $\mathrm{C} 2=3 \%$ tulsi powder sample, $\mathrm{C} 3=5 \%$ tulsi powder sample.

3.3. Cooking time Cooking time of pasta sample was significantly decreased as compare to the control sample, in each case $50 \mathrm{~g}$ of each sample was taken and cooked separately for the evaluation of cooking time. The result is shown in Table 4.

Table.4.Cooking time of prepared pasta sample

\begin{tabular}{|l|l|}
\hline sample & Cooking time (minute) \\
\hline C & $5.12 \pm 0.5$ \\
\hline C1 & $5.08 \pm 0.16$ \\
\hline C2 & $4.50 \pm 0.10$ \\
\hline C3 & $4.28 \pm 0.12$ \\
\hline
\end{tabular}

Note: All value are represented as Mean \pm S.E.M. (standard error mean), $n=6$; data were analyzed by one-way ANOVA (Analysis of variance) employing Dunnett Multiple Comparisons Test using Graph Pad, Instate 3 software, $* \mathrm{P}<0.05$.

3.4. Visco-elastic properties - Rapid visco analyzer (RVA, Starch Master of Perten, Sweden) was used to determine the pasting properties of raw material of pasta products. The peak viscosity (maximum viscosity of the sample during the heating and holding phase of the procedure) as well as the final viscosity (viscosity reading at the end of the test profile) was recorded for all samples. Sample is cooked at $95^{\circ} \mathrm{C}$ then cooled to $65^{\circ} \mathrm{C}$, and its viscosity measured, using a RVA. The paste temperature of $65^{\circ} \mathrm{C}$ is used to rapidly stabilize viscosity and minimize retro gradation. 
Table.5.Viscosity Value Of Different Samples

\begin{tabular}{|c|c|c|c|}
\hline Sample & Peak viscosity & Hold viscosity & Final viscosity \\
\hline C & $2910.66 \pm 608.93$ & $2662.00 \pm 573.505$ & $2152.66 \pm 463.78$ \\
\hline C1 & $2751.33 \pm 378.60$ & $1768.66 \pm 177.21$ & $2994.00 \pm 274.54$ \\
\hline C2 & $2902.33 \pm 247.35$ & $1827.33 \pm 165.77$ & $3119.33 \pm 221.45$ \\
\hline C3 & $4183.00 \pm 2103.58$ & $2632.33 \pm 1354.98$ & $4314.33 \pm 2008.77$ \\
\hline
\end{tabular}

It was found that there was significant difference in the peak viscosity and hold viscosity among different samples $(\mathrm{P}<0.05)$.

Table .6. Different variables of rapid viscosity Analysis

\begin{tabular}{|c|c|c|c|c|c|c|}
\hline Sample & variables & Sum of square & DF & Mean square & F Value & SIG \\
\hline \multirow[t]{3}{*}{ Peak Viscosity } & Between group & 2900104.917 & 3 & 966701.639 & .707 & .574 \\
\hline & Within group & 10932800.0 & 8 & 1366600.00 & & \\
\hline & Total & 13832904.917 & 11 & & & \\
\hline \multirow[t]{3}{*}{ Hold Viscosity } & Between group & 1326418.250 & 3 & 442139.417 & .724 & .566 \\
\hline & Within group & 4885820.667 & 8 & 610727.583 & & \\
\hline & Total & 6212238.917 & 11 & & & \\
\hline \multirow[t]{3}{*}{ Final Viscosity } & Between group & 2919810.250 & 3 & 973270.083 & .836 & .511 \\
\hline & Within group & 9318686.667 & 8 & 1164835.833 & & \\
\hline & Total & 12238496.917 & 11 & & & \\
\hline
\end{tabular}

Note: All value are represented as Mean \pm S.E.M. (standard error mean), $n=6$; data were analyzed by one-way ANOVA (Analysis of variance) employing Dunnett Multiple Comparisons Test using Graph Pad, Instate 3 software, $* \mathrm{P}<0.01$

\subsection{Texture analysis.}

The texture of the samples was analyzed and it was found that the force (in g) required to cut the pasta sample was decreasing with increasing amount of tulsi powder. The results of the analysis are presented in the table No 6. The cutting force of C, C1, C2 and C3 were 2410.12 $\pm 0.40,2392.00 \pm 1.07,2129.90 \pm 1.60,1843.00 \pm 0.87$, respectively. The increase in the percentage of tulsi powder is resulting in the softer texture of the product.

Table.7.Cutting force $(\mathrm{g})$ of the pasta samples

\begin{tabular}{|c|c|}
\hline sample & Tulsi powder \\
\hline C & $2510.18 \pm 0.020$ \\
\hline C 2 & $2496.15 \pm 1.06$ \\
\hline C 3 & $2230.88 \pm 1.58$ \\
\hline
\end{tabular}

Note: All value are represented as Mean \pm S.E.M. (standard error mean), $n=6$; data were analyzed by one-way ANOVA (Analysis of variance) employing Dunnett Multiple Comparisons Test using Graph Pad, Instate 3 software, $* \mathrm{P}<0.01$

\subsection{Sensory characteristics}

Sensory evaluation of the products was carried out by using 9 point hedonic scale sensory test. The colour score of $\mathrm{C}, \mathrm{C} 1, \mathrm{C} 2$ and $\mathrm{C} 3$ samples was $7.10 \pm 0.03,6.51 \pm 0.02,7.22 \pm 0.06,6.56 \pm 0.07$, respectively. It was observed that the colour of $\mathrm{C} 2$ was found best among all samples. The flavour score of $\mathrm{C}, \mathrm{C} 1, \mathrm{C} 2$ and $\mathrm{C} 3$ samples was $7.80 \pm 0.03,6.42 \pm 0.07,7.26 \pm 0.07,6.12 \pm 0.02$, respectively. The score of $\mathrm{C} 2$ was found best in sensory evaluation. The texture, taste and overall acceptability score of $\mathrm{C} 2$ was $7.34 \pm 0.08,7.02 \pm 0.03$, and $7.20 \pm 0.38$, respectively. There was improvement in colour and texture of the product. The taste might have some change with increasing concentration of tulsi pasta. The product with 3 percent tulsi pasta was found better in comparison to other combinations.

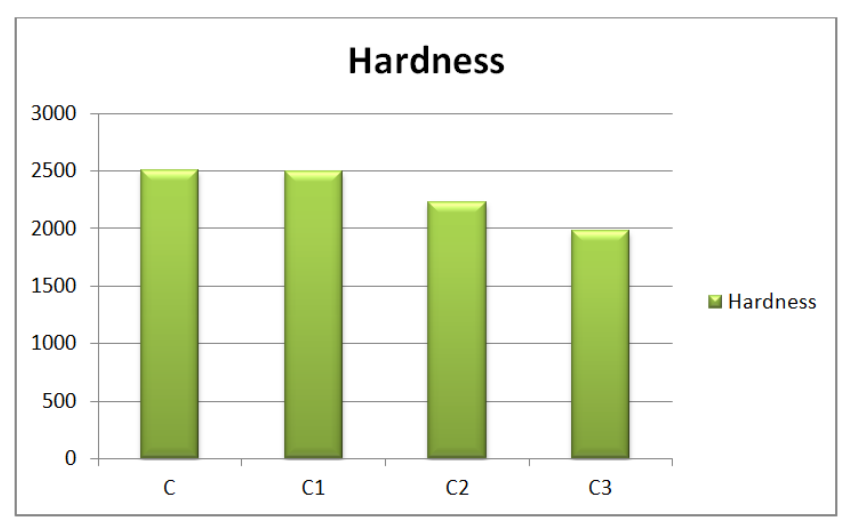

Fig 1 : Graphical representation of hardness of different pasta sample 

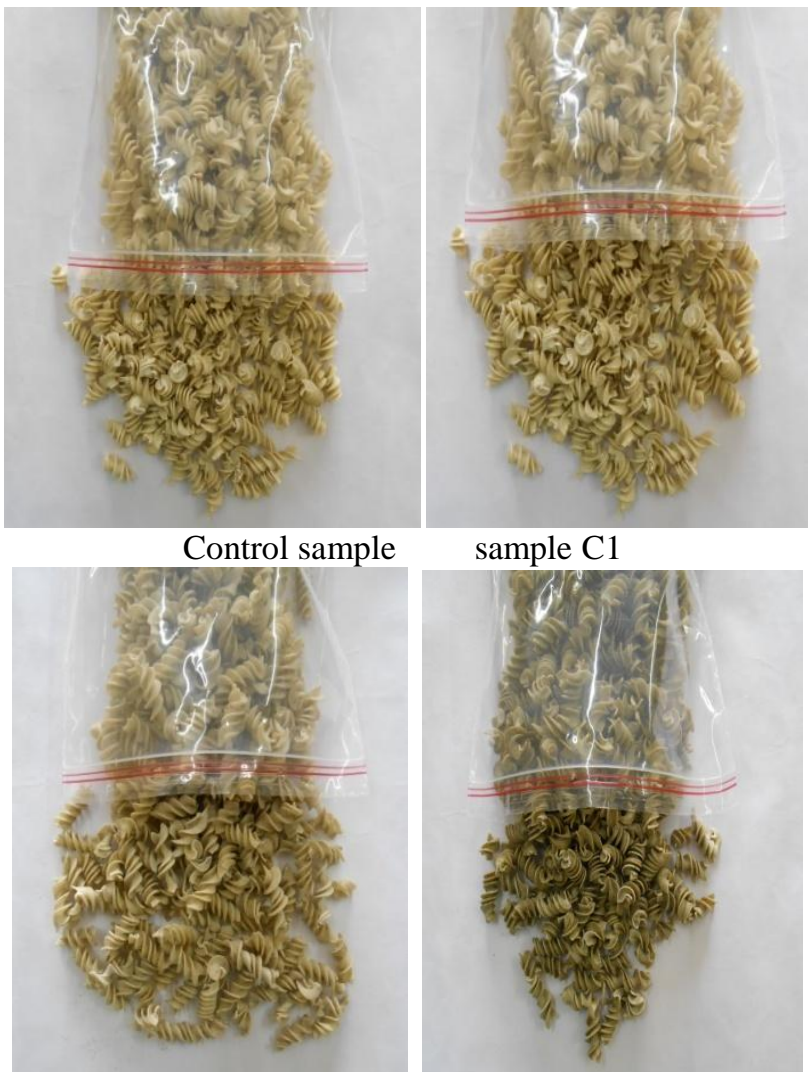

sample C1

Sample C2

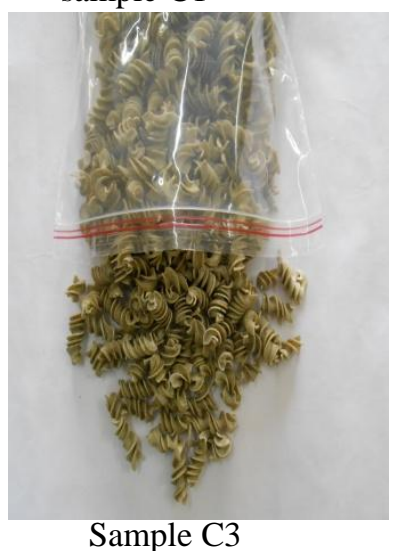

Table 8. Sensory scores of prepared pasta samples

\begin{tabular}{|l|c|c|c|c|c|}
\hline \multirow{2}{*}{ Sample } & \multicolumn{5}{|l|}{ Sensory parameters } \\
\cline { 2 - 6 } & Colour & Flavour & texture & taste & Overall acceptability \\
\hline C & $6.80 \pm 0.63$ & $6.60 \pm 0.84$ & $6.90 \pm 0.73$ & $7.10 \pm 0.73$ & $6.80 \pm 0.78$ \\
\hline C1 & $7.10 \pm 0.73$ & $7.0 \pm 0.94$ & $7.30 \pm 0.94$ & $7.60 \pm 1.17$ & $7.20 \pm 0.42$ \\
\hline C2 & $7.40 \pm 0.84$ & $7.30 \pm 0.67$ & $7.80 \pm 1.03$ & $6.90 \pm 0.99$ & $7.40 \pm 0.51$ \\
\hline C3 & $7.10 \pm 0.99$ & $7.40 \pm 0.84$ & $7.20 \pm 0.78$ & $7.20 \pm 0.78$ & $7.50 \pm 0.52$ \\
\hline
\end{tabular}

\section{Conclusion}

The pasta was prepared with different proportions of tulsi powder. The results showed that with increase in tulsi concentration the fibre content increased and the cooking time decreased and the softness of pasta increased more than the control sample. It was found that the final viscosity of the sample was increasing with increase of tulsi powder. Fortified pasta was highly acceptable with respect to sensory attribute and cooking time. On the basis of physico-chemical and nutritional properties, cooking time analysis of viscosity and sensory qualities pasta certain 97\% refine wheat flour and 3\% tulsi powder sample C2 resulted in better quality having more and high overall acceptability. tulsi powder prevents different diseases (diabetes, asthma, arthritis and heart diseases etc.). If we include tulsi powder pasta in daily life style, it's prevent many diseases.

\section{Acknowledgements}

The present study was supported by the Centre of Excellence food science and technology, Bundelkhand University Jhansi, Uttar Pradesh India, to provide the necessary research facilities for the successful completion of research work.

\section{Conflict Of Interest}

The authors declare no conflict of interest.

\section{References}

[1]. Joshi, Bishnu., Lekhak, Sunil., Sharma, Anuja.,2009, Antibacterial Property of Different Medicinal Plants: Ocimum sanctum, Cinnamomum zeylanicum, Xanthoxylum armatum and Origanum majorana,kathmandu university Journal of science, engineering and technology vol. 5,pp 143- 150.

[2]. Khanum, F.;Swamy M.S.; Sudarshana Krishna K.R.:Santhanam K and Vishwanathan K.R.,2000. Dietary fiber content of commonly fresh and cooked vegetables consumed in india. Plant food for human nutrition.55L:207-218.

[3]. Lukumual, Hakkim F., Gowri, Shankar C. and Girija, S.,2007, Chmical Composition and Antioxidant Property of Holy basil ( ocimum Sanctum L.) Leaves, Stems, and inflorescence and Their in Vitro Callus Cultures.Agric.Food Chem. 55, 9109_9117. 
[4]. Mdziniso P.,Margaret J., Hinds, Bellmer D., Brown B. and Payton M.,2006. Physical quality and carotene content of solardried green leafy and yellow succulent eatables. Plant foods for human nutrition. 61;13-21.

[5]. Merai, Mamta ; Boghra ,V. R.; Sharma ,R. S. 2003. Extraction of antioxygenic principles from Tulsi leaves and their effects on oxidative stability of ghee, Journal of food science and technology,vol.40(1), pp. 52-57

[6]. Narendhirakannan R.T., Subramanian. and Kandawamy, M.2005.Mineral Content of Some Medicinal Plants Used in the Treatment of Diabetes Mellitus. Biological Trace Element Research Vol. 103, pp 109-115.

[7]. Patel, M.M. and Rao, G.V.,1996. Effect of untreated, heat treated and germinated black ngram flours on the physiochemical and biscuit making characteristics of wheat flour, J. Food Sci. Technology. 33 (1): 53-56.

[8]. Rai. V., Iyer.U., and Mani, U.V., 1997. Effect of Tulsi leaf powder supplementation on blood sugar level,serem lipid and tissue lipid in diabetic rats. Plant food for human nutrition. 50:9-16

[9]. Singh,G. , Kawatra, Asha., Sehgal, S. And Pragati,2003. Effect of storage on nutritional composition of selected dehydrated green leafy vegetable, herb and carrot . Plant Foods for Human Nutrition 58: 1-9.

[10]. Tyler, V.,1994. Herbs of choice: The therapeutic use of phyto medicinals. Binghamton, Pharmaceutical Procuts Press, New York.

[11]. Dexter, J. E., Matsuo, R. R., and Morgan, B. C. 1983a. Spaghetti stickiness: Some factors influencing stickiness and relationship to other cooking quality characteristics. J. Food Sci. 48:1545-1551, 1559

[12]. Geetha, Kedlaya, R. and Vasudevan.,2004, Inhibition of lipid peroxidation by botanical extracts of Ocimum sanctum: In vivo and in vitro studies .J life Sciences 76:21-28.

[13]. Ghaffar, Suwaibah., AS, Abdulamir., Bakar, Fatimah Abu.,Karim, Roselina and Saari, Nazamid,2009 .Microbial Growth, Sensory Characteristic and $\mathrm{pH}$ as Potential Spoilage Indicators of Chinese Yellow Wet Noodles from Commercial Processing Plants, American Journal of Applied Sciences 6 (6): 1059-1066

[14]. Gopalan, C., Rama Sastri, B.V. and Balasubramanian, S.C.,1987. Nutritive value of Indian foods. National Institute of Nutrition (ICMR Publ.)-Hyderabad.

[15]. Gupta, S.C. and Pingale, S.V.,1970. Evaluation studies of quality characteristics of Improved indigenous Mexican Wheat varieties.Bull.Grain Technol.8(4):146-150.

[16]. Singh, M., Sharma, N.S., and Khatkar, B.S.,2006. End use quality of Indian wheats: Milling properties and Composition.J.Food Sci. Technol. 43(3):322-324

[17]. Lerdau MT, Monson RK, Pen uelas J (2011). Estimations of isoprenoid emission capacity from enclosure studies: measurements, data processing, quality and standardized measurement protocols. Biogeosciences 8:2209-2246 